\title{
Using questionnaires in research on universities: analysis of experiences from a situated perspective
}

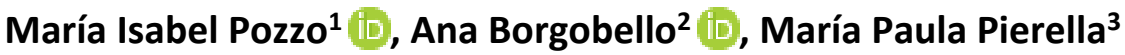 \\ Sent: 23/11/2018. Accepted: 08/04/2019. Published in press: 13/06/2019. Published: 01/07/2019
}

\section{//Abstract}

INTRODUCTION: This paper addresses the use of questionnaires in research on universities from a critical and methodological perspective.

METHOD: After a discussion of the main concepts from the literature, four studies that used questionnaires are presented: a) international research, b) a quasi-experimental study, c) a study of a sensitive topic, and d) a study based on an online questionnaire. The studies are analyzed in relation to the methodological approach, the aims of the instrument in each case, the digital or printed format of the questionnaire, and the advantages, limitations and difficulties encountered in the research task.

RESULTS and DISCUSSION: The main conclusions refer to the ambiguity of concepts and methodological approaches, the importance of interpreting data in the production context, the collaboration of respondents and bias in survey construction and data analysis.

\section{//Keywords}

University; Research; Methodology; Questionnaires; Comparative studies.

\section{//Authors' information}

${ }^{1}$ Independent researcher at the National Scientific and Technical Research Council, Argentina in the Rosario Institute of Research in Educational Sciences (IRICE). She holds a PhD in Humanities and Arts, with a major in Educational Sciences from the National University of Rosario where she is an adjunct lecturer focused on field work. She has participated in an international project on engineering education funded by the European Union. National Scientific and Technical Research Council (CONICET), Argentina. Corresponding author: maria.isabel.pozzo@gmail.com

\begin{abstract}
${ }^{2}$ Assistant researcher at the National Council of Scientific and Technical Research in the Rosario Institute of Research in Educational Sciences. She holds a PhD in Psychology from the National Louis University. She works as a lecturer in research methodology at the Psychology Faculty of the National University of Rosario. National Scientific and Technical Research Council, Argentina.

${ }^{3}$ Assistant researcher at the National Council of Scientific and Technical Research in the Rosario Institute of Research in Educational Sciences. She holds a PhD in Social Sciences from the University of Buenos Aires. She works as a lecturer in socio-education at the Educational Sciences School, Faculty of Humanities and Arts, National University of Rosario. National Scientific and Technical Research Council, Argentina.
\end{abstract}

\section{//Recommended reference}

Pozzo, M. I., Borgobello, A., and Pierella, M. P. (2019). Using questionnaires in research on universities: analysis of experiences from a situated perspective. REIRE Revista d'Innovació i Recerca en Educació, 12(2), 1-16. http://doi.org/10.1344/reire2019.12.227010

A Spanish version of this article is published in Pozzo, M., Borgobello, A., and Pierella, M. P. (2018). Uso de cuestionarios en investigaciones sobre universidad; análisis de experiencias desde una perspectiva situada. Revista Latinoamericana De Metodología De Las Ciencias Sociales, 8(2), e046. https://doi.org/10.24215/18537863e046

(c) 2019 María Isabel Pozzo et al. This is an open access article distributed under the Creative Commons Attribution-NonCommercial-ShareAlike 4.0 International License, which permits the user to share (copy and redistribute the material in any medium or format) and adapt (remix, transform, and build upon the material), provided the original work is properly cited, changes are indicated, the material is not used for commercial purposes, and the contributions (if remixed, transformed, or built upon the material) are distributed under the same license as the original. To view a copy of this license, visit http://creativecommons.org/licenses/by-nc-sa/4.0/ 
M. I. Pozzo, A. Borgobello, M. P. Pierella. Using questionnaires in research on universities: analysis of experiences from a situated perspective

//Títol

Ús de qüestionaris en recerca sobre la universitat: anàlisi d'experiències amb una perspectiva situada

//Resum

INTRODUCCIÓ: L'article fa referència a l'ús de qüestionaris en investigacions centrades en el nivell universitari des d'una perspectiva metodològica crítica.

MÈTODE: Després de discutir els conceptes principals de la literatura especialitzada, es presenten quatre estudis diferents que utilitzen aquesta tècnica. Es refereixen a l'ús d'un qüestionari: $a$ ) en una investigació internacional, $b$ ) en un estudi quasiexperimental, $c$ ) en un estudi d'un tema delicat, i $d$ ) implementat per Internet. S'analitzen en relació amb l'enfocament metodològic, els objectius de l'instrument en cada estudi i el suport en paper o digital, i també se n'estudien els avantatges, limitacions i dificultats trobats en la tasca d'investigació.

RESULTATS i DISCUSSIÓ: Les principals conclusions es refereixen a l'ambigüitat dels conceptes i els enfocaments metodològics, a la importància de llegir les dades en el context de producció, a la col-laboració dels enquestats i al biaix en l'elaboració de l'enquesta i l'anàlisi de les dades.

//Paraules clau

Universitat; Recerca; Metodologia; Qüestionaris; Estudis comparatius.

\section{//Título}

Utilizar cuestionarios en investigación en la universidad: análisis de experiencias desde una perspectiva situada

\section{//Resumen}

INTRODUCCIÓN: El artículo hace referencia al uso de cuestionarios en investigaciones centradas en el nivel universitario desde una perspectiva metodológica crítica.

MÉTODO: Después de discutir los conceptos principales de la literatura especializada, se presentan cuatro estudios diferentes que involucran el uso de esta técnica. Se refieren al uso de un cuestionario: a) en una investigación internacional, b) en un estudio cuasiexperimental, c) en un estudio de un tema delicado, y d) implementado por Internet. Se analizan en relación con el enfoque metodológico, los objetivos del instrumento en cada estudio, el soporte en papel digital, así como las ventajas, limitaciones y dificultades encontradas en el proceso de investigación.

RESULTADOS y DISCUSIÓN: Las principales conclusiones se refieren a la ambigüedad de los conceptos y de los enfoques metodológicos, a la importancia de leer los datos en el contexto de producción, a la colaboración de los encuestados y al sesgo en la elaboración de la encuesta y el análisis de los datos.

//Palabras clave

Universidad; Investigación; Metodología; Cuestionarios; Estudios comparativos. 


\section{Introduction}

Data collection is vital in scientific research to produce new knowledge. In the educational field, interviews and observations play a more significant role than surveys. Decisions on which technique to use lead to a broader discussion that, although largely resolved (Schmelkes, 2001), seems to emerge under circumstances where flexible designs are opposed to more structured ones.

During the authors' professional careers in humanities at the University of Rosario, Argentina, the academic community has been reluctant to use questionnaires in educational research. Although this situation could be considered local, it can be found in other contexts. As questionnaires are sometimes applied in an illfounded, unreflective way, this rejection is not without its rationale and justification. The aim of this paper was to discuss the controversy from a critical perspective, examining ways in which questionnaires are used in educational research. We considered the advantages and disadvantages of questionnaire use in university research from a methodological perspective, using specific, problematic examples. In the studies that are discussed, the analyses focused on ecological adaptation to the research object rather than the mathematization of the questionnaire in the sense of measuring or testing it. Hence, each study was contextualized succinctly within the framework in which it was developed.

The organizational differences between universities and teacher profiles make heterogeneity the most outstanding feature of educational institutions. Consequently, it is difficult to consider focused studies from the perspective of research. The use of questionnaires allows a broader approach to this range of contexts and realities. This dimension must be considered when we address studies that go beyond the analysis of a case. Due to their scope, these studies allow information to be obtained from subjects belonging to tribes (Becher, 2001) that are distant from each other in disciplinary and institutional terms, among other advantages.

However, the topic must be approached in a context where virtuality and digital media are involved in almost all human activity and, consequently, in research. The usefulness of automated procedures associated with software for administering and processing surveys has been questioned. Instruments that are initially considered satisfactory can have limitations. This idea is prominent in literature on the qualitative approach.

The next section of the paper is a theoretical and methodological review to clarify concepts that are often used interchangeably but should be differentiated. The paper continues with four studies in which questionnaires were used, to identify contextualized advantages and disadvantages. The article concludes with a discussion of the advantages and limitations of this technique for research in the university context.

\section{The questionnaire as a methodological strategy}

The terms "survey" and "questionnaire" are often used indiscriminately. Although there is considerable variation in discussions of this subject, "survey" generally refers to the method, while "questionnaire" refers to the specific instrument that is applied.

Hernández-Sampieri, Fernández-Collado and Baptista-Lucio (2008) suggest that questionnaires consist of a series of open and/or closed questions on one or more than one variable, and they are probably the most 
commonly used instrument for data collection. However, Archenti (2007) refers to polls or surveys, on the same level, as methods for collecting data on attitudes, beliefs or opinions through standardized questionnaires.

Psychometrics, which tests work based on specific scales, can be considered the origin of the concept of standardization. Standardization applies to questionnaires when, for example, a reliability coefficient is determined. In general and in this paper, standardization relates to the idea of protocol, that is, repetition of highly similar applications in different cases.

Regarding terminology, Hernández-Sampieri et al. (2008) consider that opinion surveys are nonexperimental, cross-sectional, descriptive or correlational-causal investigations that generally use questionnaires. Beyond the specificity of the subject matter, which is discussed later in this section, it is significant that these authors equate surveys with a certain type of research.

More generally, Canales, Alvarado and Pineda (1994) claim that surveys are a way of gathering opinions, attitudes, knowledge or suggestions about the topics under study. For these authors, the questionnaire is a method that uses an instrument or printed form, which respondents complete individually, to obtain information about the problem under study.

To summarize, questionnaires are described in even the most classic research methodology books as the instrument itself, as a method, a design, a type of research, a standardized instrument and a structured interview, among others. These different ways of understanding the subject matter justify the present review.

Even considering the multiplicity of meanings, the questionnaire is conceived in this paper as an instrument designed within the framework of a research project based on specific objectives.

One aspect that can be considered essential, given that it is mentioned frequently in research methodology books, refers to the advantages and disadvantages of using questionnaires to produce scientific knowledge. As questionnaires are easily converted into statistical databases, they can be used to make predictions with statistical support. According to Archenti (2007), the advantage of prediction, with a margin of error that can be calculated, is the main attraction of the survey as a method.

Some advantages of self-administered questionnaires are commonly reported and include: the costs are relatively low; information about a large number of people can be gathered in a short time; the data is easy to obtain, quantify, analyze and interpret; individual rates of response are respected; limited human resources are required; anonymity can be maintained and certain interviewer biases are eliminated (e.g. Canales et al., 1994; Díaz, 2012; Hernández-Sampieri et al., 2008).

Online questionnaires have additional advantages, such as immediacy of data processing, reduction of field work, the possibility of introducing audiovisual elements that aid understanding, and lower research costs. Any intimidation that could be caused by the presence of a surveyor is eliminated. The absence of a surveyor also provides an additional guarantee of anonymity that helps respondents to express more critical, less socially accepted or more sensitive responses (Coomber, 1997; Díaz, 2012). In a classic text on the subject, Coomber (1997) stresses that online questionnaires can access populations that are hard to reach for geographical reasons or due to illegal or sensitive issues. The expansion of geographical area 
facilitates international studies that only require the additional measure of translating the questionnaire text.

However, other authors have highlighted the limitations of online surveys (Canales et al., 1994; Coomber 1997; Díaz, 2012; Hernández Sampieri et al., 2008). These include: limited flexibility and difficulty in deepening the information that is obtained; risk of not reaching the intended recipients or not getting a response; inability to clarify doubts about the questions; difficulty in obtaining a high rate of complete questionnaires. Those who voluntarily respond, and those who do not, may have different opinions or predominant characteristics that affect the research (Coomber, 1997). Online questionnaires can be affected by connectivity errors and little control over respondents, so the samples obtained are not reliable. An additional problem of the digital medium is that recipients may suspect that the questionnaire is a virus and not respond.

Online and printed questionnaire formats share some advantages and limitations. However, the medium that is used is relevant from a methodological perspective, in terms of the number of responses, representativeness, possibility of rewording the question, and other factors.

Although the implementation of online questionnaires is now common in Latin America, the number of published papers that have used this technique is low in comparison with the English-speaking academic world, where there was earlier mass access to the internet. This gap is illustrated by the fact that the year Coomber (1997) reported on the possibilities of the internet for online questionnaires, the Government of Argentina, according to De-Sena and Lisdero (2015), declared its interest in internet access and began to develop a strategic plan for it. Despite this gap, online questionnaires are now part of regular strategies in social research. Furthermore, a considerable amount of software is available to create the methodological conditions required to administer online questionnaires (De-Sena and Lisdero, 2015).

\section{Studies that use questionnaires in the university}

In this section, we consider some studies that used questionnaires as a methodological strategy, to focus the discussion on specific cases. In the first study, a satisfaction questionnaire was administered to an international sample from various geographical areas over two years. The second addresses sensitive topics for respondents. The third refers to an online questionnaire administered to university teachers and introduces problems relating to virtual media. The last case highlights the use of questionnaires in a quasiexperimental design in which participants had a range of professional profiles.

To facilitate comparisons, the information is organized into the following areas: the context of the study; the theoretical and methodological framework; the survey objectives; the type of medium (printed or online); and the advantages, limitations, and difficulties in the research. Despite the diversity of the studies, all were designed ad hoc for the research (i.e. they were non-standardized), were based on a complex dialectical approach (Achilli, 2005) and were developed and administered in university situations.

\section{A satisfaction questionnaire in an international study}

Satisfaction questionnaires reveal the most about the respondents' opinions. Although they are generally used in commerce and business, their application in education is increasing. Due to their 
characteristics, they are suitable for evaluative research and are administered after implementation of the element that is being evaluated: a teaching intervention, a teaching resource, teaching methodology, etc. A discussion of the connotations of satisfaction questionnaires, which goes beyond the scope of this study, could hypothesize about a conception of education that is more closely linked to merchandise than to a service.

The design and implementation of the first study was part of an international research project. Entitled "Educational modules for electric and electronic circuits theory and practice following an enquiry-based teaching and learning methodology supported by VISIR (VISIR+)", the project was coordinated by Dr. Gustavo R. Alves from the Polytechnic Institute of Porto, Portugal. It ran for twoand-a-half years from October 2015 until April 2018. It was funded by the European Union through the Erasmus+ Programme's "Capacity building in the field of higher education" instrument. The aim was to expand to Latin America the implementation of the Virtual Instrument Systems in Reality (VISIR) remote laboratory, which was created in the Blekinge Institute of Technology, Sweden, by a team led by Ingvar Gustavsson. In Latin America, the VISIR would be used in the training of electrical and electronic engineers and the teaching of physics in related careers. For this purpose, the research focused on higher education institutions in Argentina and Brazil that were taken as case studies, based on experience with this resource in four European universities in Sweden, Austria, Spain and Portugal. The gradual, step-by-step implementation required constant monitoring to assure that the chosen educational perspective (referred to in the title) had been applied in each context. It was assumed that the dissemination process required evaluation in various training instances. To verify the quality of the teaching and learning process, a mixed quantitative and qualitative approach was used with various data collection instruments, as well as other sources of spontaneous evidence. One form of data collection was the use of satisfaction questionnaires; other techniques included class (training session) observations, interviews and document analysis (educational modules and teaching plans). This section addresses the satisfaction questionnaires used at the end of each training session.

The first reason for administering a printed version of the questionnaire was to ensure the mass participation of those at the event. Another reason was that printed questionnaires can be implemented at the right time; in this case, at the end of the training sessions when the participants still had a vivid memory of the experience. The online version was only used for the online mode of the training session or for those who were absent when the questionnaire was administered.

The use of a standardized instrument meant that comparable information could be gathered to evaluate implementation in different contexts: in two dissimilar countries (Brazil and Argentina), in different types of institutions (private and public, universities and colleges), at different times and by different trainers. If a standardized instrument had not been used, the process would have resulted in numerous empirical records that would have been difficult to process and transcribe. The process may even have been made impossible by the distances in time and space. Instead, the use of a standardized instrument meant that data could be gathered from distant sources. The following description illustrates the temporal and spatial range. The questionnaire was administered after the first training action, which consisted of two sessions that deserved to be evaluated separately, due to their characteristics and dissimilar speakers. The sixty questionnaires that were collected were completed by online and on-site attendees from Latin America and Europe in Sessions 1 and 2. 
The second training action was carried out in different Latin American higher education institutions. Although the training sessions were not performed simultaneously, they were held over two months, as in the other countries. Therefore, there was uniformity in the project timeline. The difference in the number of respondents was due to the idiosyncrasy of each institution and region. Another advantage of questionnaires is that respondents can express nuances in their degree of satisfaction. The range of options on a Likert scale can counteract the limitations of a closed instrument.

Indeed, predetermined answers limit opportunities to explain certain perceptions. However, the inclusion of one or two open questions at the end of the questionnaire redressed this limitation. Respondents' cooperation was required to take advantage of the open questions and answer them as fully as possible.

Within the standardization that characterizes this methodological tool, the questionnaire design should address the nature of the dimensions that are evaluated. Thus, for example, when the instructor's sensitivity to training participants' interests and concerns was assessed, the values offered as options in the questionnaire were: Unsatisfactory, Below average, Average, Above average, Excellent. However, these options were not applicable to the question about whether the training sessions met respondents' expectations. For this question, the range of possible answers was: Not at all, Partially, Satisfactorily, Very satisfactorily, Completely. Another question focused on the degree of difficulty in the use of the educational resource. In this case, the options were: Too difficult, Difficult, Normal, Easy, Too easy.

The methodological issues that are presented here may seem evident. However, undifferentiated design of the instrument, without adaptation of questions and answers, can confuse respondents and waste the opportunity to gather their opinions. Questions about difficulty with the values of unsatisfactory, below average, etc. offered as answers would result in incongruity that would undermine the validity of the collected information.

The translation of the questionnaire, especially the response options, was another challenge. Some expressions such as unsatisfactory, excellent and difficult were transparent in the translation from one language to another (in this case, from English to Portuguese and Spanish). However, others raised questions about frequency of use in each linguistic community. Thus, while average and below average are commonly used in the Anglo-Saxon speaking community, their textual translation is not as common in the Spanish-speaking countries. To match the answers, a literal translation was chosen.

\section{Use of a questionnaire to examine a sensitive topic}

This project was an exploratory, descriptive study about dishonest academic practice among students at a public university in Argentina. The sample was composed of 560 psychology students. Students observed and reported their partners' and their own dishonest behavior. Therefore, the general aim of the study was to identify and analyze students' conscious or unconscious rulebreaking practices, according to their own reports.

A complex approach was used in this study with a printed survey containing open and closed questions. Senior students' opinions were requested after the results had been shared with them by 
email. The original questionnaire was written in Spain, created by Sureda-Negre, Comas-Forgas and Gili-Planas (2009), and modified for use in the Argentinean academic environment. The Spanish questionnaire only examined dishonest behavior during exams. In the local version, open questions were inserted before the closed questions and were subsequently coded and analyzed through a content analysis technique. Students were asked to give examples of their own or other students' dishonest behavior during exams or written reports, and to explain why they or their peers acted in this way (Espinosa, Castellarin and Biagioni, 2013; Peralta, Ventura, Borgobello and Espinosa, 2014).

Eighty per cent of students stated that they never copied from a classmate during an exam. However, $78 \%$ affirmed that they had witnessed a classmate cheating. A similar situation occurred with the use of "machetes or chuletas" (crib sheets to copy from during a test). Although most students claimed not to have used this cheating method, they reported that they had witnessed others using crib sheets frequently. Furthermore, over half of the students (53\%) stated they had allowed classmates to copy from their exam. This percentage of students seems to hide the real behavior.

Senior students commenting on the results concluded that there is a tendency to hide one's own misbehavior while reporting that of others: "I think the result shows that, in general, bad behavior (cheating, using "machetes") tends to be hidden when it is the individual carrying out the act, while there is no problem in highlighting someone else's misbehavior" (sic).

Students suggested that copying others' work was a personal decision based on responsibility and maturity. Nonetheless, some students asserted that cheating was related with class content, the teacher, and knowledge of students' interests.

This questionnaire's original design meant that students' own behavior and that of their peers could be identified (Sureda et al., 2009). Open questions were added to analyze the context in which the behavior occurred (Espinosa et al., 2013; Peralta et al., 2014). Another methodological advantage was the symbolic bridge that was built with other scientists and situations by taking an existing instrument and adding inquiry methods through a qualitative and critical perspective.

The type of questions used limited the technique to enquiries about the social situation, resulting in little data on academic practices. Once this limitation was perceived by the research team, and due to the flexibility of the qualitative research methods, new ways of questioning were designed. To gather more complex data, the initial results were shared with students by email and their conclusions were obtained for the research project.

Another critical factor was the students' skepticism about questionnaires in the institution where the research was carried out. This skepticism may have been due to the training students received in psychoanalytical and qualitative techniques during their university courses. This attitude could be observed during the administration of the questionnaire in students' comments and written responses. These factors can cause difficulties in the design and selection of methodological strategies to meet research objectives. 
In a project carried out at IRICE-CONICET/UNR, an online questionnaire was administered to first year lecturers from a range of degree courses and fields. The main objective was to identify lecturers' opinions of various dimensions of teaching activities, specifically the epistemological, disciplinary, pedagogical, ethical and political implications. The qualitative research was designed to gather biographic data, life plans, training, and academic and professional experiences.

Questionnaires were not used at the start of the project, when Glaser and Strauss's (1967) Grounded Theory was adopted. However, the project conceptualization took into account the data. The narrative interview (Bertaux, 2005) was the main data collection technique used to examine interviewees' professional lives. The field work was carried out at three colleges of a public university in Rosario, Argentina. The sample was selected considering a range of knowledge areas. Twenty-five interviews were held with lecturers, deans and academic secretaries, considering age, school, position, discipline and seniority.

Once the interviews and data analysis had been completed, a complementary data collection technique was added: the questionnaire. Even though the interview sample was small, significant information was obtained about interviewees' professional experiences. One of the main factors in the survey design was the difficulty of obtaining official data from schools about first-year lecturers' profiles. The instrument was administered online, considering the aforementioned advantages of the online medium. The survey had 23 closed questions and one open question to obtain comments or clarification about the previous answers.

Beyond the lecturers' sociodemographic characteristics, work conditions and professional habits, the questions were designed to obtain information about perceptions of first-year teaching. The degree of satisfaction with job conditions was determined and other aspects considered were working hours and salary, infrastructure and relationships among lecturers on the same courses. At the same time, political and social aspects of university policies were examined, such as opinions of the admissions process. Since the mid-twentieth century, Argentina has implemented a non-selective admission process mainly in the public education system. The only admission requirement is graduation from secondary education. This type of admission, which allows social mobility, was interrupted during the dictatorships and reinstated during democratic governments. Now, university admission is a controversial debate. The use of direct questions on this topic could have led to socially accepted answers, while the use of indirect questions could have caused problems with clarity. This dilemma was solved by choosing categories that already exist in literature on the topic. The admissions options that participants could choose from were:

- Which admission process do you agree with?

- Restrictive and limited vacancy admission test

- Restrictive admission test

- Non-restrictive test

- Supported and direct enrollment

- Direct enrollment 
This instrument had a limitation. When the responses were analyzed, it was observed that most participants (47 \%) agreed with the "supported and direct enrollment" option. However, in the open question relating to the above multiple-choice question, one respondent expressed doubts about the meaning of this category. This led the research team to evaluate the use of the categories drawn from the literature. If the questions had been written with more detailed or popular language, unnecessary doubts could have been avoided. This situation highlights one of the most common problems of online surveys: how to get people who are not directly available to discuss doubts generated by the instrument (Díaz, 2012).

It was important to analyze teachers' explanations of the first-year dropout rate in Argentina as it stands at around $40 \%$. The aim was to understand the scope of this phenomenon in relation to students' and/or institutional responsibilities. Specific literature on the topic was used to inform the researchers' approaches. An ordinal scale for multiple-choice questions was applied to determine the weight of different factors in the lecturers' opinion:

In your opinion and experience, please rank how each factor influences students' withdrawal:

- Vocational problems

- Family's socioeconomical situation

- Learning disabilities (writing, reading, comprehension and study habit problems)

- Academic requirements (timing and environment of study)

- Lack of previous knowledge

- Difficulties with rules when admitted to a new institution

- Difficulties in passing tests and/or examinations

- Difficulties related to the curriculum

- Difficulties related to course content

- Difficulties related to teaching styles

In this kind of question with multiple variables, a respondent's answers should be checked against each other during the analysis. Interviews reveal the interviewees' overall perceptions, but questionnaires interpreted with bivariate statistics lose the respondents' singularity. The use of specific statistics could help to identify individual profiles.

\section{Questionnaire in a quasi-experimental study}

This study was part of a doctoral thesis project by one of the authors. The aim was to analyse new teachers' tutorial functions at university level, and the study focused on specific teaching roles in a controlled situation (Borgobello, 2010; Borgobello, Peralta and Roselli, 2013).

The experiment was replicated twice: with social sciences students and with students from the hard sciences. In each case, teachers had to lecture on the same topic to ten randomly distributed students. The participants were a senior lecturer (who was used to giving theoretical lectures), a 
graduate teaching assistant (used to working with a small number of students in laboratories and/or workshops), and a student teaching assistant (who was not allowed to be in charge of a class, but collaborated with students and teachers' assistants in laboratories or workshops).

A week before the experiment, the goal of the project was introduced to the participants. The original text from which the post-test questions were taken was given to teachers. Classes were recorded for subsequent transcription. The transcriptions were assessed by five external experts who did not know the nature of the experiment or the levels of the teachers' expertise.

This study focused on the premise in sociocultural psychology that the teaching and learning process is constituted within a social space in a particular form (Borgobello et al., 2013). According to González-Rey (2008), forms of action are subjective settings that are embedded in the social context of people's vital plot and social life.

Therefore, the aim of the experiment was to analyze teaching practices that could not commonly be observed in natural settings because, for example, teaching assistants are not allowed to teach. The number of students and the base text was maintained in the experimental design in the three groups. The learning and assessment processes in the lessons were compared and social interaction was observed and analyzed.

Four printed questionnaires were designed. These included a general pretest to evaluate prior knowledge with open questions and a post-test based on the source text with multiple choice questions. Clarity and conceptual depth in the three transcribed classes were analyzed by five external experts in each case. Through the questionnaire, students evaluated the class and their own assessment. The main advantage of using a questionnaire was to compare the three classes in each case, which was the main goal of the pretest and post-test design. This type of design was meant to compare what is naturally incomparable and created equal situations for people who regularly perform unequal teaching roles.

Despite the equal setting provided, the results of the external experts' assessments and other analyses showed characteristics of the regular teaching roles adopted by the participants. For example, classes taught by the main teachers were explanatory lectures even when they were in front of just ten students (Borgobello, 2010; Borgobello et al., 2013). This type of quasi-experimental design allows us to consider the establishment of teaching practice, and reveals similarities among cases and actions beyond the specific contexts in which these practices are usually developed. The results showed that teachers maintained their teaching characteristics regardless of the number of students in the classes. The teachers in the study regularly give explanatory lecturers as class sizes tend to be large. This experiment indicates that teaching roles are embodied in our teaching practice (either theoretical or practical classes) and are not altered even when there is an evident change in context (for example, in the experiment each teacher worked with just ten students).

In the experiment, students obtained better learning results when they were taught by students rather than by the main teachers. This could be due to the fact that teaching assistants followed the source text more closely than the main teachers. Usually, assessed content is found in texts rather than in the lectures given by the main teachers. These results do not prove the irrelevance of the 
lectures, given that lectures put the texts in a broader context. Nevertheless, they do show the importance of a range of roles and team work.

One of the most relevant theoretical discussions relating to this study is the measurement of learning through questionnaires. The post-test, administered after the classes, did not measure actual learning, but immediate recall. Therefore, the concept of learning, at least from a constructivist framework, is so complex that it cannot be memorized, and, even less, determined from an immediate memory (Borgobello, 2010).

Regarding the construction of the instruments, the questionnaire for the comparative assessment of the classes created by the external experts generated the greatest difficulties. To meet the experiments' objectives, all the classes had to be tested with the same questionnaire, and yet we had experts in two highly dissimilar areas of knowledge and participants from different academic and institutional cultures. The questionnaire had to be a unique and simple instrument for both cases to be easily understood (Borgobello, 2010; Borgobello et al., 2013). This required several pilot tests to adjust the language to both fields of sciences. Finally, the experts had the opportunity to justify their decisions and add comments as necessary, thus giving respondents greater freedom and providing useful qualitative data to understand the answers comparatively.

The fact that social sciences students were not familiar with answering closed-question tests to assess knowledge was an additional difficulty in this study. Although the group of expert volunteers collaborated extensively with the research, the type of instrument generated a certain degree of resistance.

\section{Discussion and conclusions}

In this paper, we use examples to discuss the advantages and limitations of the use of questionnaires in university-level research. We highlight the terminological and methodological ambiguity (Archenti, 2007; Canales et al., 1994; Hernández-Sampieri et al., 2008) implicit in the terms "survey" and "questionnaire" which can be instruments, techniques, strategies, methods, designs and types of research. Although there is general agreement on the advantages and limitations (Canales et al., 1994; Coomber, 1997; Díaz, 2012; Hernández-Sampieri et al., 2008), the underlying theoretical and methodological question seems to be that this topic is insufficiently problematized. Consequently, four studies were examined in which questionnaires were used, considered as instruments or techniques in the framework of the survey as a method. The limitations in each case showed that questionnaires should be conceived as complex approaches, rather than a single technique. Case studies were used to base the discussion on real research experiences. The paradigmatic situations that were presented were:

- An international study applied in an extensive temporal, geographic and linguistic area to analyze participants' satisfaction with their training.

- A study on sensitive issues for respondents; in this case, academic dishonesty in university students.

- An online inquiry for first-year university teachers to investigate their work performance.

- A quasi-experimental study to analyze teaching practices in different roles within the organizational structure of the university chair. 
The studies were selected to include various research teams, dissimilar subjects within the university and varied research procedures. In each study, the questionnaire respondents had different profiles: lecturers in a training situation, first-year university lecturers, undergraduate students at different points in their degree, and expert evaluators. Although diversity was the main feature during the selection of the studies, there were also two common points. The first was a complex approach (Achilli, 2005) adopted by research teams who had been trained in qualitative data analysis. The second feature, which was not far from the aforementioned theoretical and methodological orientation, was that all the questionnaires were designed ad hoc, that is, they were not standardized in a classical sense.

The research was organized into five areas of analysis: the studies' setting and context of implementation; the theoretical and methodological approach; the objectives of the instruments within each study; the characteristics of the medium; and the advantages, limitations and difficulties encountered in the research task.

The institutional contexts of the studies in which the use of questionnaires was analyzed were: an international organization supporting a research project involving higher education institutions from six countries; a specific college; and a national research organization.

The common characteristic of the projects' theoretical and methodological approach was a complex dialectical construction (Achilli, 2005), beyond the noticeable divergence between the framework of the research projects.

Regarding each project's objectives and instruments, the first study was designed to broaden the area of use of an educational resource. In this case, the questionnaire was designed to determine the degree of satisfaction with the resource and the training.

The second study aimed to identify and analyze students' opinions of dishonest practices. It also examined the administration of the questionnaire, with a focus on collecting students' examples of dishonest behavior in a range of circumstances, such as academic writing and group work. The frequency and type of dishonest behavior were investigated in written exams.

The online questionnaire project focused on first-year teachers' opinions of the dimensions of university education. This study sought to identify working conditions, lecturers' perceptions of teaching in the early university years and their opinions about first-year students considering the difficulties and challenges of the transition.

The questionnaires that were used in the last study came from a project centered on analyzing the tutorial functions of teaching assistants through a multi-method approach (the study of document sources, ethnographic and experimental designs). The aim was to compare the lectures of three teachers who worked in different roles and disciplines ( $3 \times 2$ design). One of the instruments assessed students' previous knowledge (pretest), another was based on external experts' evaluations of the topics addressed during the classes, the third focused on measuring learning (post-test) and the last instrument assessed classes from the students' perspective.

The questionnaires were administered in printed format, digital format or a combination of both (traditional and online with restricted access). The questionnaire as a technique allowed equal 
measurement and comparison, for example, when evaluating implementation in different contexts, institutions, moments and training sessions or when an experimental situation was designed with the corresponding controls. Another evident technical advantage in almost all cases was that questionnaires enabled nuances to be expressed about the degree of satisfaction, while restricting the degrees of assessment. In the study on academic dishonesty, the original design of the instrument made it possible to investigate behavior that is usually hidden.

In projects with a complex approach, the use of open-ended questions led to discussion and to the incorporation of qualitative and contextual aspects in the analyses. Anonymity (reinforced by mass implementation and the type of medium, depending on the case) allowed free expression of opinions on delicate issues and sensitive moral aspects, so that respondents did not give politically correct answers.

The questionnaire that was implemented online could reach, through institutional intermediaries, teachers who would not otherwise have been accessed. In other words, by sending a single email, all the teachers could be accessed through a reliable source. Additionally, the collection of answers did not require intermediaries.

Negative aspects were broken down into limitations and difficulties. The limitations refer to the design stage, while the difficulties refer to the administration of questionnaires. In the design stage, some studies revealed a need to verify the correspondence between the questions and response options. In other studies (specifically the one on sensitive topics), the type of questions was insufficient to consider the context of the investigated practices in the social research area. This limitation was solved through other predominantly qualitative methods of inquiry via email.

In the design phase of the international study, the importance of preserving semantic nuances in translated questions was considered. Another of the limitations was how well questions were understood when categories were retrieved from theoretical sources or used assiduously by researchers. This could be overcome in future applications by using more general language or expanding the explanations in the questions themselves. Finally, another limitation was that the singularity of respondents was lost in favor of the totality of answers.

Regarding difficulties in the implementation phase, the studies indicate that there was not always sufficient cooperation in responses, especially to open-ended questions. In the study on sensitive issues, the type of instrument was rejected to a certain extent in an institution characterized by a predominantly qualitative and psychoanalytical tradition. An additional implementation difficulty was the limited familiarity of human sciences students with closed questions. This difficulty was also encountered in cases such as the evaluation of knowledge in the quasi-experimental design and the study on dishonesty. In the experimental study, the obstacle was that the questionnaire itself had to be evaluated by experts in two dissimilar areas of knowledge, therefore, clarification was permitted.

One conclusion from the analysis is the need to read results in context. A clear example can be seen in the study comparing teaching roles, in which students were found to have "learned more" in classes with teaching assistants. However, more experienced teachers contextualized class content, which gave students the opportunity to learn beyond immediate recall. In general terms, a degree of insufficiency in the richness of the data was perceived. More elaborate interpretations could have been generated from the informants' responses. 
Regardless of when a questionnaire is administered, the timing is a specific requirement in flexible approaches such as those presented here to anticipate possible answers, and even the future of research when the implementation is long term.

Criticisms of questionnaires do not tend to refer to the nature of the instrument itself, but to its creation and/or limited or untidy use. Thus, technical disadvantages are confused with the carelessness of those who design and/or implement questionnaires.

The questionnaire is usually conceived as an instrument that eludes researcher's bias given its usual protocol. However, the bias of those who produce it is generally not considered, as if the product were free of values. Questions about perceptions, representations and beliefs point to the subjective nature of the answers that are often overlooked in some interpretations that associate responses with reality. This illusion of transparency can have different origins, ranging from ingenuity to data manipulation, reinforcing arguments through the legitimacy provided by empirical studies. Further examples of this topic that should be dealt with in future research include: the pressure experienced by respondents in the presence of the researcher, the situation in which answers to a questionnaire can have an impact on job stability or academic performance and solidarity or identification between those involved.

\section{$<$ References $>$}

Achilli, E. (2005). Investigar en antropología social. Los desafíos de transmitir un oficio. Rosario: Laborde.

Archenti, N. (2007). El sondeo. In A. Marradi, N. Archenti \& J. I. Piovani (eds.), Metodología de la Ciencias Sociales (pp. 203-214). Buenos Aires: Emecé.

Becher, T. (2001). Tribus y territorios académicos. La indagación intelectual y las culturas de las disciplinas. Barcelona: Gedisa.

Bertaux, D. (2005). Los relatos de vida. Perspectiva etnosociológica. Barcelona: Ediciones Bellaterra.

Borgobello, A. (2010). Las mediaciones tutoriales en la enseñanza universitaria: el rol de los auxiliares de primera y de segunda en la UNR. (PhD thesis) Universidad Nacional de San Luis, Argentina.

Borgobello, A., Peralta, N., \& Roselli, N. (2013). Interaction among experience, teaching performance and student's learning at university level. Estudos de Psicologia, 30(1), 169-176. https://dx.doi.org/10.1590/s0103-166×2013000200003

Canales, F., Alvarado, E., \& Pineda, E. (1994). Metodología de la investigación. Manual para el desarrollo de personal de salud. Washington: OPS.

Coomber, R. (1997). Using the Internet for Survey Research. Sociological Research Online, 2(2), 1-18.

De-Sena, A., \& Lisdero, P. (2015). Etnografía virtual: aportes para su discusión y diseño. In A. De-Sena, Caminos cualitativos (pp. 71-100). Buenos Aires: Ciccus.

Díaz, V. (2012). Ventajas e inconvenientes de la encuesta por Internet. Papers, 97(1), 193-223. https://dx.doi.org/10.5565/rev/papers/v97n1.71 
M. I. Pozzo, A. Borgobello, M. P. Pierella. Using questionnaires in research on universities: analysis of experiences from a situated perspective

Espinosa, A., Castellarin, M., \& Biagioni, F. (2013). Prácticas académicas deshonestas en exámenes escritos. Análisis de una muestra de alumnos de primer año de la Carrera de Psicología de la UNR. Paper presented in V Congreso Internacional de Investigación y Práctica Profesional en Psicología. Buenos Aires: Ediciones de la Facultad de Psicología. Retrieved from http://sedici.unlp.edu.ar/handle/10915/52277

Glaser, B., \& Strauss, A. (1967). The discovery of grounded theory: strategies for qualitative research. New York: Aldine.

González-Rey, F. (2008). Subjetividad social, sujeto y representaciones sociales. Diversitas: Perspectivas en Psicología, 4(2), 225-243. https://dx.doi.org/10.15332/s1794-9998.2008.0002.01

Hernández-Sampieri, R., Fernández-Collado, C., \& Baptista-Lucio, M. P. (2008). Metodología de la investigación. México: McGrawHill.

Peralta, N., Ventura, A. C., Borgobello, A., \& Espinosa, A. (2014). Análisis descriptivo de las posibles prácticas académicas deshonestas de los estudiantes de sexto año de psicología según sus propias opiniones. In C. López, L. Bulacio \& M. Migliaro (coord.), Divulgación de la producción científica y tecnológica de la UNR (pp. 643-646). Rosario: UNR Editora.

Schmelkes, S. (2001). La combinación de estrategias cuantitativas y cualitativas en la investigación educativa: Reflexiones a partir de tres estudios. Revista Electrónica de Investigación Educativa, 3(2), 82-94. Retrieved from http://www.redalyc.org/pdf/155/15503205.pdf

Sureda-Negre, J., Comas-Forgas, R., \& Gili-Planas, M. (2009). Prácticas académicas deshonestas en el desarrollo de exámenes entre el alumnado universitario español. Estudios sobre Educación, 17(1), 103-122.

\section{$<$ Supporting agencies $>$}

The research was supported by the Argentinian National Scientific and Technical Research Council; and the European Commission's Erasmus+ Programme, through its "Capacity building in the field of higher education" instrument. 